\title{
Application of the Integrative Procedure for MANAgEMENT OF Production AND SERVICE IMPROVEMENT PROCESS ON THE ASSEMBLY LINE
}

\author{
Nikola Gjeldum, Marko Mladineo, Marina Crnjac \& Amanda Aljinovic
}
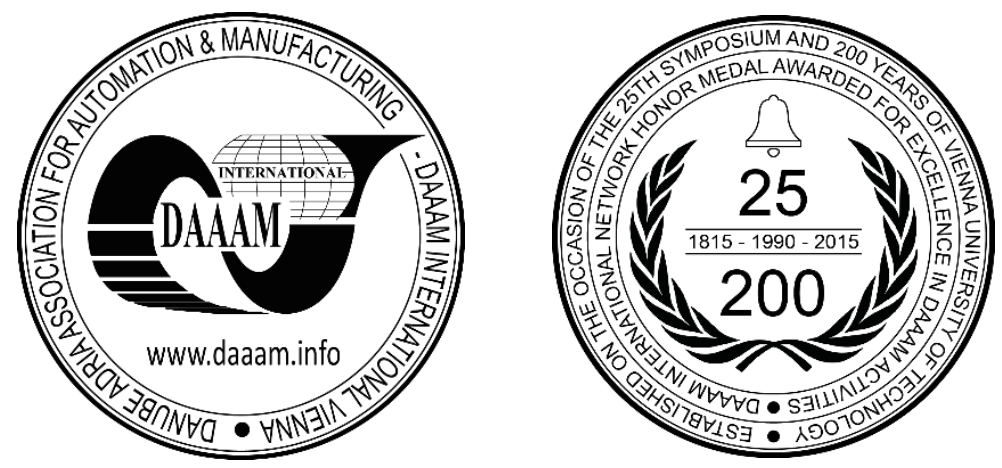

This Publication has to be referred as: Gjeldum, N[ikola]; Mladineo, M[arko]; Crnjac, M[arina] \& Aljinovic, A[manda] (2018). Application of the Integrative Procedure for Management of Production and Service Improvement Process on the Assembly Line, Proceedings of the 29th DAAAM International Symposium, pp.0031-0040, B. Katalinic (Ed.), Published by DAAAM International, ISBN 978-3-902734-20-4, ISSN 1726-9679, Vienna, Austria DOI: $10.2507 / 29$ th.daaam.proceedings.005

\begin{abstract}
Continual improvement of production process consists of small incremental improvements combined with breakthrough improvement steps. These improvements are usually achieved through the improvement of the organization, processes and people skills using improvement concepts like Lean management. Sometimes, usually for breakthrough improvements, significant financial investments in technology are needed. On the other hand, improving of organization, processes and people skills usually do not require significant financial investments. Therefore, for industrial enterprises, it would be the most valuable to have a procedure for the management of the continual improvement process. The procedure that identifies and focuses on the most important processes or part of processes and selects the improvement action which will have the best effect on key performance indicators (KPIs) of the production process. In this research, an integrative procedure for management of production and service improvement process is experimentally tested on the real assembly line in the Laboratory at FESB, University of Split. The focus of this paper is on the innovative multicriteria decision making support system for prioritization of proposed improvement processes, based on the HUMANT algorithm. The result is that one proposed improvement process is selected as the most effective solution, according to pre-defined KPIs.
\end{abstract}

Keywords: improvement process; lean management; multi-criteria decision-making; assembly; HUMANT algorithm

\section{Introduction}

Today, the main challenge for every enterprise is to succeed in a turbulent business environment where all competitors have similar opportunities, and where customer wants personalized product instead of products produced in mass production systems. The ability to customize a product or service is offered to consumers for many years now, while truly unique products will be requested in the near future by users around the globe using the Internet as a means of integration in the design process [1]. Employees and their competences play a strong role in enterprises survival by its involvement in the continual improvement process. Nevertheless, one of the possible conceptions for the survival in a turbulent world market is the introduction of new technologies and organizational structures. 
Lean management concept is understood as the realization of Lean principles through the efficient application of methods and tools in order to detect and eliminate losses in production and service processes. Lean management utilizes methods and principles to model an improved future state which has to be realized in order to improve production efficiency. Many companies are guided by the example of Toyota production system. They invest very large amount of resources and efforts in the development of their own efficient production systems and its implementation. Design and implementation of such a customized program for continuous improvement can significantly reduce production losses and the company can be more competitive in the market [2].

Previous research confirms that the base principles of Toyota Production System (TPS) and Lean Management (LM) principles appear in 30 multinational companies [3]. All interviewed managers of production systems belong to the group of leading companies in the world. They are from different industries and different countries. On the other hand, according to a conducted survey presented in [4], only $2.5 \%$ of interviewed companies in Croatia have introduced Lean management principles inside of its manufacturing processes. Encouraging is that $23 \%$ of companies use some of the Lean principles. One of the most used method is Just-in-time, as many Croatian enterprises are suppliers to automobile industries. On the other hand, $74.5 \%$ of companies, mainly small and medium enterprises do not use any of LM or TPS principles or methods at all [4]. Mentioned studies indicate a need for further research to assist Croatian companies in finding their way for improvement toward efficient production or service systems. There are five basic principles of the Lean management according to [5], and those are: value from the customer perspective, mapping the value stream, continuous flow, pull and strive for perfection. Teams have to be formed in all levels of the company, and the goal is that these teams solve problems on the daily basis [2]. Lean principles have been accepted by a large number of people who solve the problems they face in a business environment. This is the motive for the fight against outdated principles used by employees because they have a fear of something new. A detailed explanation about the benefits of using and implementing Lean principles can create an acceptable atmosphere to employees and encourage them to progress. On the foundations of Lean production, the company can build smart production. Simple information systems are changing to the smart platform which leads to the fourth industrial revolution, or "Industry 4.0" concept. Civilization has already witnessed three industrial revolutions, which could also be described as disruptive leaps in industrial processes resulting in significantly higher productivity [6]. The first improved efficiency through the use of hydropower, the increasing use of steam power and the development of machine tools. The second brought electricity and mass production through assembly lines, and the third and most recent further accelerated automation using electronics and IT technology. In the fourth industrial revolution, physical objects are being seamlessly integrated into the information network. The Internet is combining with intelligent machines, systems and production processes to form a sophisticated network. The essence of the Industry 4.0 vision is in the Internet of things and Internet of services, which means the ubiquitous connectivity of people, things and machines [7]. Companies indicate standardization as a most important precondition for Industry 4.0. Standardized systems, platforms, processes and interfaces make a crucial infrastructure for easier implementation of Industry 4.0 [6].

When continual improvement is introduced into an organization, it is not uncommon to encounter difficulties such as senior management fails to provide the necessary leadership by establishing sustained high-level commitment and enthusiasm for the program. Mapping the value stream becomes a goal rather than a tool to use in working towards goals. Teams over-analyse problems rather than focusing on results-oriented solutions and too much time is spent criticizing the current process [8]. Potocki in [9] mentioned organizational improvement approach as a system of management: strategic in nature, open to the environment, cyclical in operation by producing output and receiving feedback, striving for equilibrium, and seeking optimization. Continual improvement of production processes consists of incremental and breakthrough improvement steps. Value stream consists of activities that add value (value added) to product or service and activities that do not add value (non-value added) to product or process. Non-value added activities could be eliminated if those are assorted as waste. Nevertheless, improved processes can be a part of other value streams, therefore improving productivity and overall equipment effectiveness for other production lines. Large improvement steps have to be managed by middle and top management, but small improvement steps can be initialized by blue collar, i. e. personnel that actually work on that process. Blue-collar personnel unlikely propose improvements that require high investment costs. On the other hand management personnel is not aware of problems and obstacles preventing smooth and optimized process One approach is using Kaizen, which is a Japanese word for continuous improvement. It originates from the Toyota production system and means business philosophy of constantly working on small improvements.

\section{DEPROCIM project: Methodology and objectives}

The "Development of integrative procedure for management of production and service improvement process (DEPROCIM)" project is a scientific-research project funded by Unity Through Knowledge Fund (UKF). The project aim is to define and propose an integrative procedure i.e. framework for continual improvement process in production or service processes, which will take into consideration value from the customer perspective, current production plans and scheduling, on-time delivery, work-in-process inventory, capacity utilization, throughput and other relevant manufacturing metrics. The procedure should utilize information and communication technology for collecting data, prior to Lean management principles and methods for detecting needs for improvement. The needs should be sorted and analysed. Different proposed improvements should be evaluated. The improvement outcome should be estimated, because only quantitative data can be a measure for production process optimization [10], [11]. 
According to developed innovative multi-criteria decision making process, overall priority for improvement should be defined, followed by the Pareto front of other improvements. The defined procedure should be validated and tested in the laboratory environment. The procedure should be applied for existing production and assembly line, with respect to available resources. Chosen improvements should be implemented, and achieved performance indicators should be measured. The field test of proposed procedure should be implemented in partner organization, in respect to its' current available resources. The proposed model, or its parts, should be designed on the way to be easily implemented in small, medium and large enterprises in Croatia (i.e. in developing country [12]) even those that did not use any of LM or TPS methods before in improvement processes. Therefore, the proposed project approach includes case studies analysis.

First of all, the block diagram of the integrative procedure for management of the continual improvement process (DEPROCIM procedure) has been defined with all the steps and processes. Then, whole procedure has been divided into the four main procedure steps (Fig. 1).

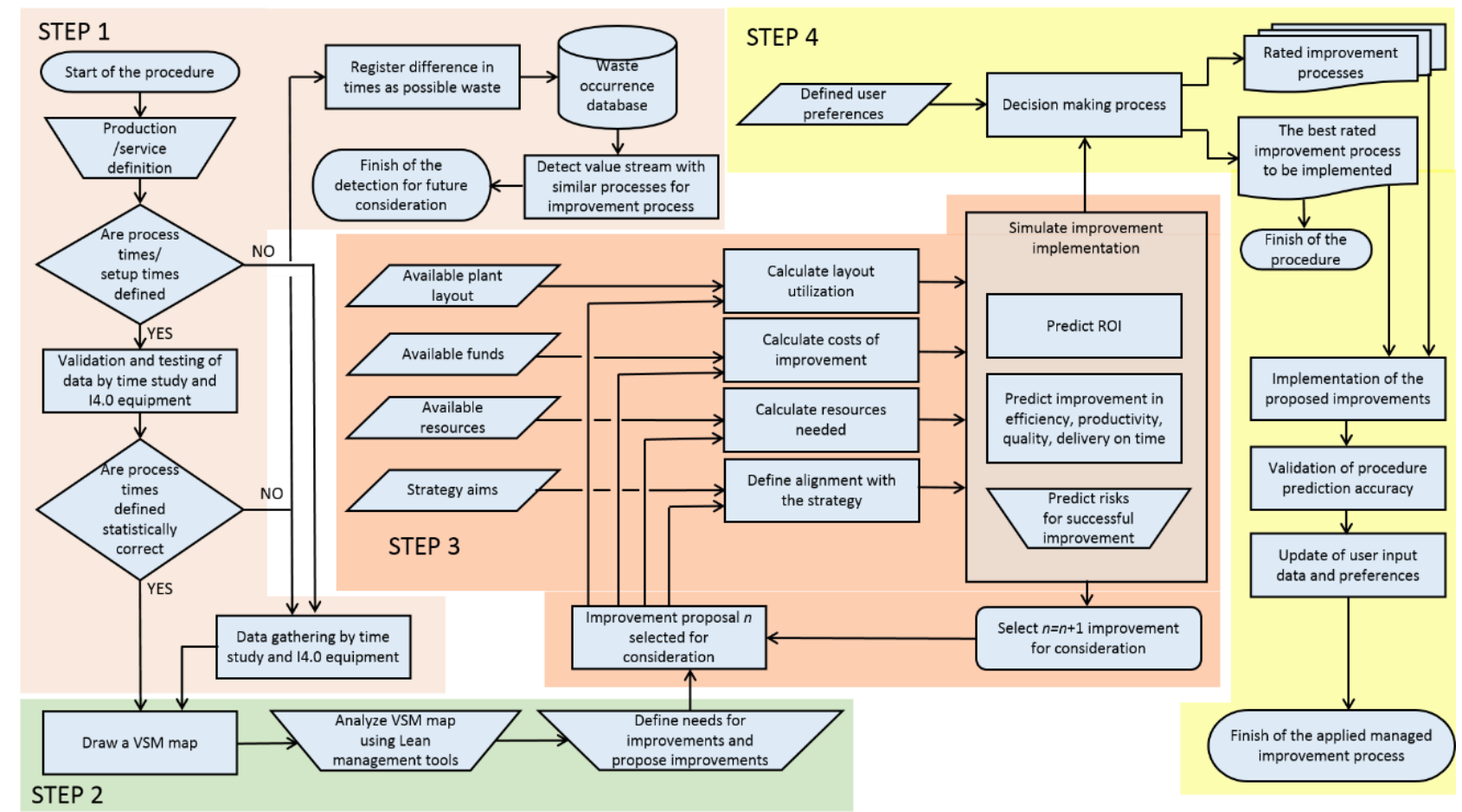

Fig. 1. DEPROCIM procedure steps in details

In the first procedure step, the information technology (IT) is utilized for collecting process data during case study analysis. Any kind of the workplace IT equipment (sensors of presence, ultrasonic sensors, counters, RFID readers, switches, keyboards, led displays and touchscreens) is used for entering and receiving data from the centralized computer. Wired and/or wireless communication protocols are used for communication with microcontroller boards and shields. The input devices on working places are enabling the inputs necessary for the study of work and time methods analyses. On that way, variations among normal process times which appears occasionally during batch production could be entered by workers. Other data and process times should be automatically detected in a real-time manner and communicated to the main computer without the involvement of worker.

The second procedure step is the mapping of processes according to the Lean management method Value Stream Mapping (VSM). VSM is a method for analysing the current state of material and information flow and creating a future state according to Lean tools and methods. It also originates from the Toyota production system and big attention is given to establish flow, eliminating waste and adding value. For future state map it is important to [13]: produce to takt time, develop continuous flow, use supermarkets to control production where continuous flow does not extend upstream, schedule based on the pacemaker operation, produce different products at a uniform rate, level the production load on the pacemaker process, develop the capability to make every part every interval period. Value stream mapping uses specific symbols, so the maps could be understandable to everyone [13].

The third procedure step involves a different applicable Lean method for determination of needs for improvement. According to analysis results of the current state, the needs for improvement are sorted and grouped. This step includes the development and modelling of organizational improvements and parts handling and transportation equipment design. On the other hand, development and detail design plans are made for manual and automatic working places and assembly working stations that will be implemented within investigated case studies. Different proposed improvements should be evaluated for every need for improvement. 
The fourth procedure step is in the focus of this paper and involves innovative multi-criteria decision making process with the optimization algorithm. Optimization algorithms deal with optimization problems in different areas and applications, from engineering design to economics and everyday life (telecommunication routing, trip planning, etc.). Most real-world optimizations are very complex and are accompanied by numerous constraints where such optimizations are solved using a highly efficient metaheuristic algorithm [14]. Different objectives are often conflicting, so finding an optimal solution or even near-optimal solutions can be a hard task. There are many applications of metaheuristic algorithms to different multi-objective optimization problems, but no known universal multi-objective metaheuristic optimization algorithm is able to solve most of the multi-objective optimization problems. Generally, multi-objective optimization methods are classified based on three different approaches [14]: a priori approach - decision-maker provides preferences before the optimization process; a posteriori approach - the optimization process determines a set of Pareto solutions [15], and then the decision-maker chooses a solution from the set of solutions provided by the algorithm [16]; and interactive approach - there is progressive interaction between the decision-maker and the solver, i.e. knowledge gained during the optimization process helps the decision-maker to define the preferences. However, decision-makers preferences are usually known in real-world problems [17], therefore, an a priori approach seems to be ideal for realworld applications. A priori approach to multi-objective optimization means that a particular single-objective metaheuristic algorithm is combined with a MCDM method. Such algorithms are Multi Objective Ant Colony Optimization (MOACO) [18] or Progressive Multi-Objective Optimization (PMOO) [19]. Furthermore, when considering the a priori approach, any of the popular metaheuristic algorithms can be used for multi-objective optimization [20], but has to be combined with a MCDM method in the appropriate manner. Multi-Criteria (Multi-Attribute or Multi-Objective) Decision-Making (MCDM) consists of the selection of the best compromise among alternatives, comparison and ranking of alternatives, or comparison of alternatives with some referent points (sorting of alternatives) [21]. Generally, MCDM methods can be divided into following groups based on their characteristics: based on utility functions - MAUT, outranking methods [21] - AHP, ELECTRE, PROMETHEE, TOPSIS, and interactive methods - VIMDA. The main disadvantage of all these MCDM methods is that their scope is Multi-Criteria problems with the finite number of alternatives, usually 10-30 alternatives, and very rarely more than 100 . So, in combination with the metaheuristic algorithm, a limited number of near-optimal solutions found by metaheuristic algorithm should be submitted to some MCDM method. Since there is no single optimal solution to the multi-objective problem, a set of solutions is defined as the Pareto optimal solutions. A solution is Pareto optimal if a given objective (criterion) cannot be improved without degrading other objectives (criteria). This set of solutions represents a compromise between different conflicting objectives (criteria). The main goal is to obtain the Pareto optimal set and, subsequently, the Pareto frontier. However, there can theoretically be a single solution to some combinatorial optimization problems. There is no best solution based on each criterion, but an overall best solution is based on decision-maker preferences, obtained using a MCDM method. Such approach is called the MCDM a priori approach to solving Multi-Objective optimization problems. The HUMANT algorithm [22] represents interesting a priori approach to single-objective and multi-objective optimization based on the idea of combining Ant Colony Optimization (ACO) [23] and the multi-criteria decision-making PROMETHEE method [21] for solving multi-objective optimization problems. This combination allows artificial ants to use multi-criteria decision-making, which is actually a human attribute, so the algorithm was called HUMANT (HUManoid ANT) algorithm. It is a specialized single-objective and multi-objective metaheuristic algorithm that can solve complex optimization problems [24]. Any optimization problem that can be presented as mathematical graph, can be solved using the HUMANT algorithm. Its main advantage that it can integrate decision-makers preferences into the optimization procedure.

To facilitate usage of the DEPROCIM procedure an innovative multi-criteria decision making support system for prioritization of proposed improvement processes has been developing. The prioritization of the proposed improvement variants, and selection of the variant with the highest priority, is made by using the HUMANT algorithm. The concept of decision support system has been developed and the prototype of user-friendly interface (Web application) has been made. The Web application uses the HUMANT algorithm via the prototype of the Web Service (asmx) which returns the solution of the priority selection problem, found by the HUMANT algorithm, in the form of $x m l$ file (Fig. 2).

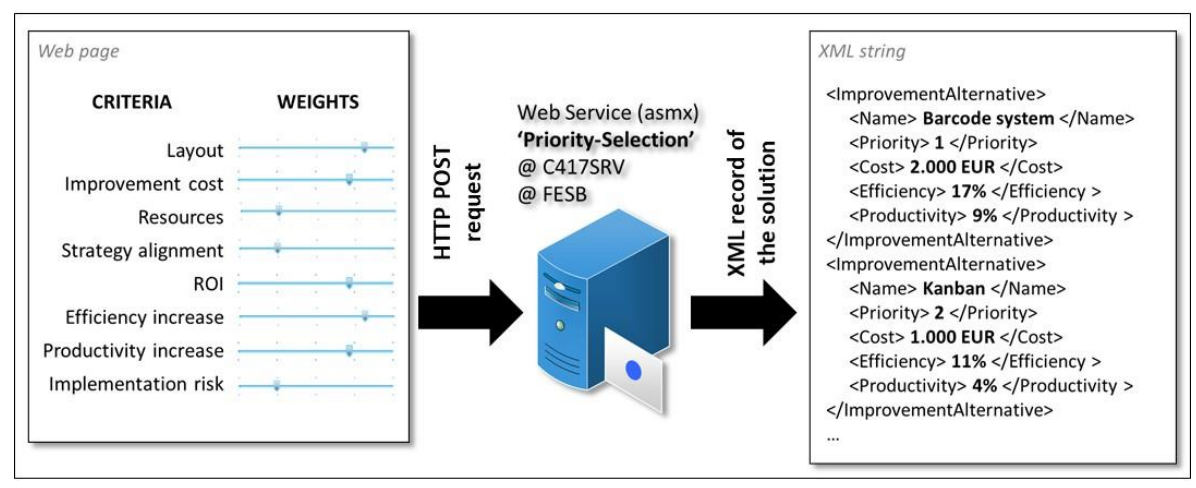

Fig. 2. Developed prototype of the Web application and service as a part of DEPROCIM decision support system 
In this research, DEPROCIM procedure has been applied on existing gearbox assembly line at FESB, University of Split. For this assembly line, the improvement variants have been defined and the optimal one has been selected, as presented in following paragraphs.

\section{Case Study: Gearbox assembly line at FESB, University of Split}

The gearbox presented in this study is a mechanical device is a part of a car, and it is made up of a large number of different gears and other parts. Fig. 3 shows the outer and inner look of the assembled gearbox. It is a multi-stage product, which means that the assembly process takes place in several steps. In this assembly line, a degree of installation is 5, which means that the gearbox assembly process is conducting in five operations steps, on five work stations (Fig. 4). The assembly line is part of the Laboratory for Industrial Engineering at FESB, University of Split.
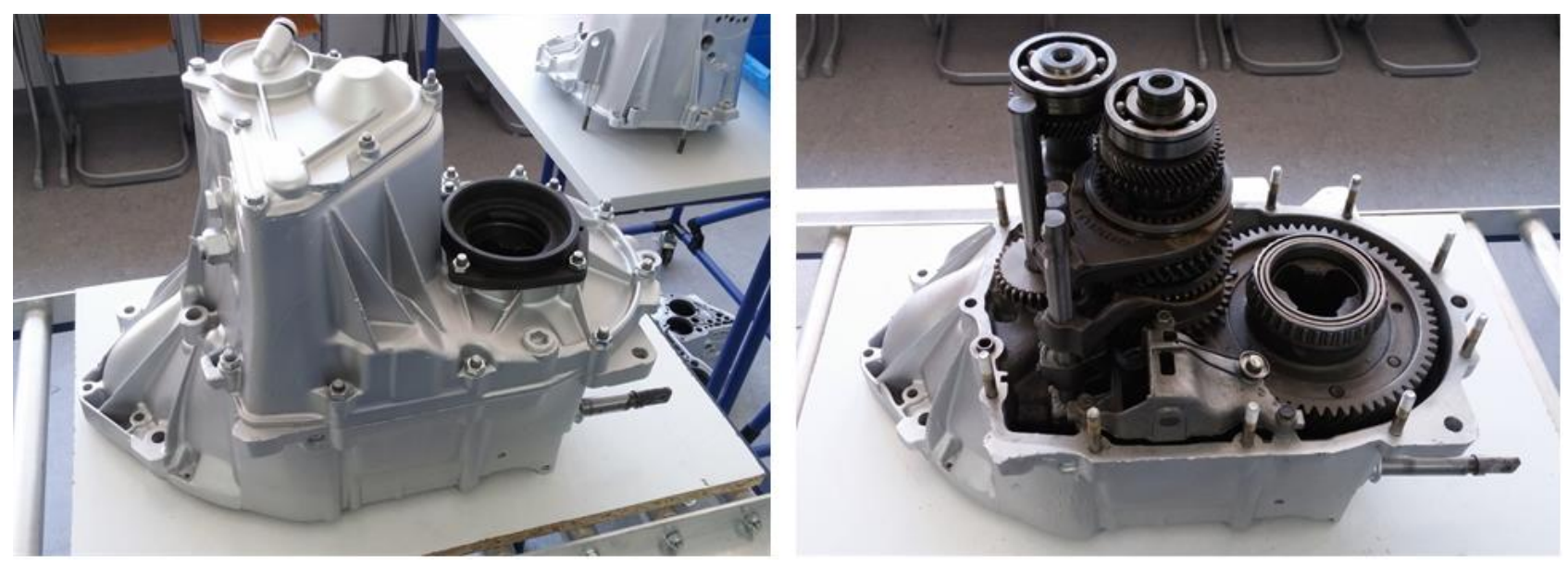

Fig. 3. Assembled gearbox

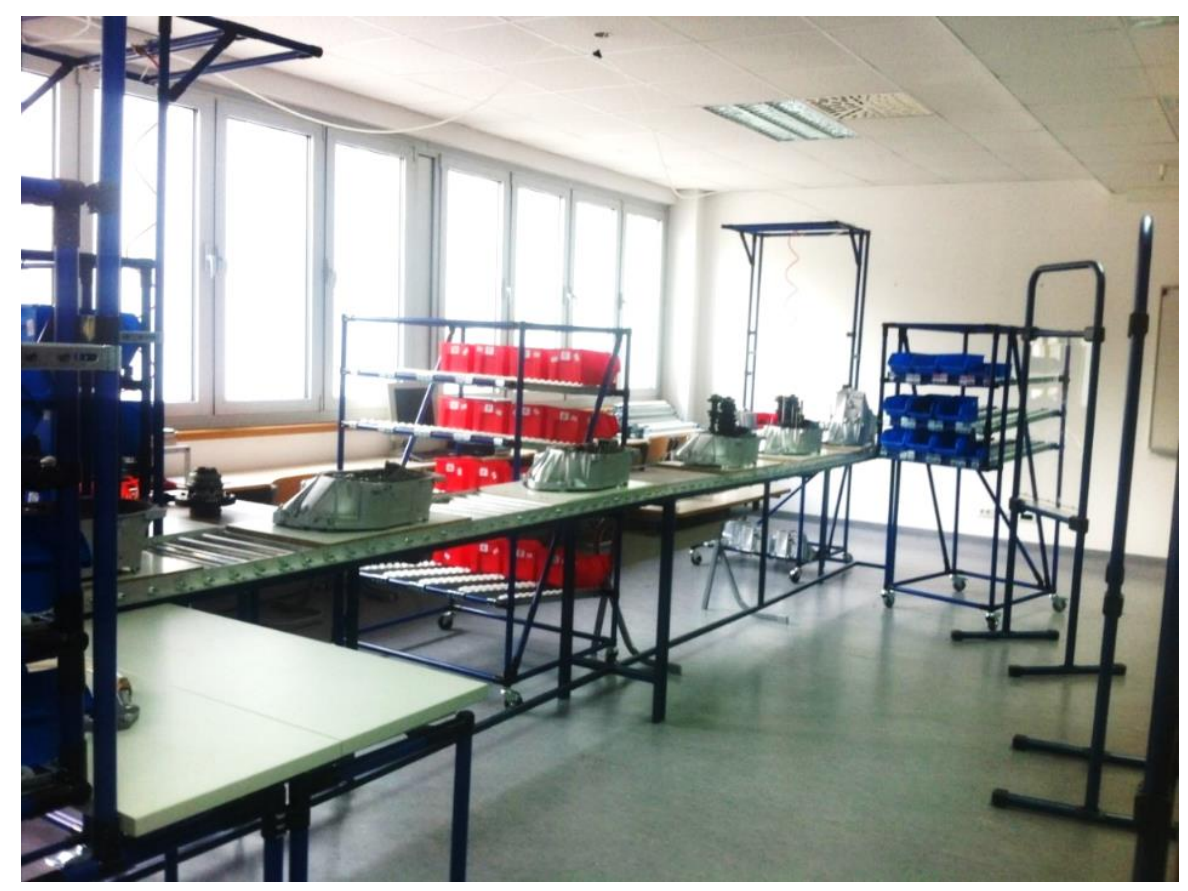

Fig. 4. Gearbox assembly line at FESB, University of Split

This assembly line has been analysed according to first two steps of the integrative procedure for management of the continual improvement process (Fig. 1). The process/setup times were collected [25] ( $1^{\text {st }}$ step of the procedure) and the process was mapped by using the operation process chart ( $2^{\text {nd }}$ step). The following improvement aims were defined:

- increase productivity,

- enable variability/changeability of products to be assembled,

- decrease the number of employees to run assembly line, 
- decrease the effort of logistic personnel,

- decrease preparation time of workers for different products,

- increase automatic process data gathering and analysis possibilities,

- improve workload balancing among assembly stations.

Taking into account defined improvement aims, strategic aims for the assembly line future development, and constraints (available layout, available funds, and available resources) six improvement variants (alternatives) have been proposed. The proposal of the improvement variants, six of them in this case, represents $3^{\text {rd }}$ step of the procedure. The variants have been described in Table 1.

\begin{tabular}{|c|c|c|}
\hline Improvement variant description & Simulated implementation outcomes & $\begin{array}{l}\text { Technology / } \\
\text { Equipment }\end{array}$ \\
\hline $\begin{array}{l}\text { Variant 1: Development, purchasing and } \\
\text { installation of devices with multiple torque } \\
\text { controlled spindles for screwing large } \\
\text { number of nuts on three positions: } \\
\text { differential device, casing } 1 \text { and casing } 2 \text {. } \\
\text { Smart module detect products assembled, } \\
\text { and therefore reports process times, waiting } \\
\text { times and lead times. RFID system needed } \\
\text { for detection of products entering the } \\
\text { assembly line. }\end{array}$ & $\begin{array}{l}\text { Reduction of workload effort on three } \\
\text { positions for } 65 \% \text {, reduction of screwing } \\
\text { process times for } 80 \% \text {. Reduction of tact } \\
\text { time for } 5 \% \text {. Larger misbalance among } \\
\text { stations. Same number of workers }(6) \text {, } \\
\text { workers should be shortly educated to use } \\
\text { devices for screwing. Three real time data } \\
\text { gathered. }\end{array}$ & $\begin{array}{l}\text { Torque controlled } \\
\text { spindles } \\
\text { RFID system }\end{array}$ \\
\hline $\begin{array}{l}\text { Variant 2: Development and installation of } \\
\text { conveyer and platforms with continuous } \\
\text { travel speed, tracked by developed RFID } \\
\text { data gathering system. This is including } \\
\text { flexible work amount on working stations } \\
\text { and adaptive resource working activities } \\
\text { according to the positions on conveyer. }\end{array}$ & $\begin{array}{l}\text { Increase of mental workload effort on all } \\
\text { positions for average } 15 \% \text {. Reduction of } \\
\text { workers idle time on two positions for } \\
20 \% \text {. Reduction of tact time for } 21 \% \text {. No } \\
\text { disbalance among stations. Same number of } \\
\text { workers (6), workers should be intensively } \\
\text { educated to work as a team. Three real time } \\
\text { data gathered. Self-organizational issues } \\
\text { expected. }\end{array}$ & $\begin{array}{c}\text { Conveyer } \\
\text { RFID system }\end{array}$ \\
\hline $\begin{array}{l}\text { Variant 3: Purchasing and installation of } \\
\text { collaborative robots on working station } \\
\text { with excessive number of nuts to be } \\
\text { screwed, and in work station with large } \\
\text { numbers of parts to be assembled in form of } \\
\text { pyramid. }\end{array}$ & $\begin{array}{l}\text { Reduction of workload effort on three } \\
\text { positions for } 70 \% \text {. Reduction of tact time } \\
\text { for } 16 \% \text {. Slightly higher disbalance among } \\
\text { stations. Reduced number of workers to } 4 \text {, } \\
\text { workers should be shortly educated to work } \\
\text { and to check work of collaborative robots. } \\
\text { Three real time data gathered. }\end{array}$ & Collaborative robot \\
\hline $\begin{array}{l}\text { Variant 4: Development and installation of } \\
\text { display guidance for workers to enable } \\
\text { flexible work amount on working stations } \\
\text { and adaptive number of parts on working } \\
\text { stations. It is monitored and driven by RFID } \\
\text { system. Collaborative manipulator } \\
\text { development and installation on working } \\
\text { station with heavy parts. }\end{array}$ & $\begin{array}{l}\text { Reduction of workload effort on one } \\
\text { position for } 40 \% \text {. Reduction of tact time for } \\
21 \% \text {. No disbalance among stations. Same } \\
\text { number of workers (6), workers should be } \\
\text { very shortly educated to use additional } \\
\text { functionalities of the system. Four real time } \\
\text { data gathered. }\end{array}$ & $\begin{array}{l}\text { Collaborative } \\
\text { manipulator } \\
\text { Display guiadance } \\
\text { RFID system }\end{array}$ \\
\hline $\begin{array}{l}\text { Variant 5: Development and installation of } \\
\text { material handling system for increased } \\
\text { speed and accuracy of material and parts } \\
\text { delivery on assembly stations' } \\
\text { supermarkets. Development of electronic } \\
\text { warehouse level triggers for self-organizing } \\
\text { supply process. }\end{array}$ & $\begin{array}{l}\text { Reduction of workload effort in logistic } \\
\text { process by } 80 \% \text {. No reduction of tact time. } \\
\text { Reduced disbalance among workers by } \\
\text { periodicaly realocatins of workers on } \\
\text { logistics processes. Reduced number of } \\
\text { workers to 5, workers should be very } \\
\text { shortly educated to balance their workload } \\
\text { on two positions. Four real time data } \\
\text { gathered. }\end{array}$ & $\begin{array}{c}\text { Material handling system } \\
\text { Self-organizing supply } \\
\text { process }\end{array}$ \\
\hline
\end{tabular}




\begin{tabular}{|l|l|l|}
\hline Variant 6: Increase of number of working & $\begin{array}{l}\text { No reduction of workload effort. Reduction } \\
\text { of tact of } 40 \% \text {. Higly reduced disbalance } \\
\text { stations for lower work load on every } \\
\text { working station, enabling individual } \\
\text { working station with adaptable work load } \\
\text { workers to 9, workers should be very } \\
\text { that includes parts from upstream and } \\
\text { shortly educated to to use additional } \\
\text { functionalities of the system. Four real time } \\
\text { downstream neighbor work stations in one. }\end{array}$ & Display guidance \\
$\begin{array}{l}\text { Development and installation of display } \\
\text { guidance for workers to enable flexible } \\
\text { work amount on working stations and } \\
\text { adaptive number of parts on working } \\
\text { stations. }\end{array}$ & & \\
\hline
\end{tabular}

Table 1. Proposed improvement variants for the gearbox assembly line

\section{Results}

The $4^{\text {th }}$ step of the procedure is the decision-making, i.e. selection of the improvement variant with highest priority (rank). The six improvement variants have been proposed for the gearbox assembly line. Each variant has been described by six measurable attributes: reliability of system, flexibility of system, equipment cost, and layout utilization. These four attributes represent four criteria and their evaluations represent an input table (Table 2) for the multi-criteria decisionmaking algorithm.

\begin{tabular}{|l|c|c|c|c|}
\hline \multirow{2}{*}{$\begin{array}{c}\text { Improvement } \\
\text { variant } \\
\text { name }\end{array}$} & \multicolumn{4}{|c|}{ Variants' attributes (criteria) } \\
\cline { 2 - 5 } & $\begin{array}{c}\text { Reliability of } \\
\text { system } \\
(\mathbf{1 - 1 0})\end{array}$ & $\begin{array}{c}\text { Flexibility of } \\
\text { system } \\
(\mathbf{1 - 1 0})\end{array}$ & $\begin{array}{c}\text { Equipment } \\
\text { cost } \\
\text { (EUR) }\end{array}$ & $\begin{array}{c}\text { Layout } \\
\text { utilization } \\
\text { (\% of current) }\end{array}$ \\
\hline Variant 1 & 8 & 1 & 14200 & 100 \\
\hline Variant 2 & 6 & 9 & 4400 & 160 \\
\hline Variant 3 & 9 & 6 & 55000 & 90 \\
\hline Variant 4 & 9 & 9 & 6800 & 115 \\
\hline Variant 5 & 7 & 5 & 6500 & 110 \\
\hline Variant 6 & 10 & 6 & 11400 & 170 \\
\hline
\end{tabular}

Table 2. Improvement variants (alternatives) with their attributes: reliability, flexibility, cost and layout utilization

However, data presented in Table 2 are objective data on the improvement variants, and the missing data are the subjective decision-maker's preferences. By defining the decision-maker's preferences, a subjectivism enters the analysis. This subjectivism is crucial, because decision-maker (production manager or technology director) can assign his/her subjective weight to each criterion, depending on the strategy, possibilities and constraints of the company. For instance, if the company is willing to invest a lot into production improvement solutions, then criterion "cost" gets a low weight, because the company will spend as much as needed to improve their production. On the other hand, sometimes a lowcost improvement are needed, and in that case the criterion "cost" will get a high weight. So, this subjectivism is something really important in this step of the production process improvement.

Since, the HUMANT algorithm will be used to solve this decision-making problem, some criteria parameters must be also defined. The HUMANT algorithm for preference distribution uses linear preference function of the PROMETHEE method, therefore indifference and preference threshold need to be defined. All criteria parameters for this decisionmaking problem are given in Table 3.

In order to facilitate the defining of the criteria weights, the user-friendly interface (Web application) was designed (Fig. 5) as a part of the DEPROCIM project. However, some additional attributes are also taken into account as a criteria. In this case, the decision-maker can favourite some equipment type, like for instance the "RFID system", and he/she can also define weight for this additional criteria. It is a kind of approach already used for the product configuration optimization [26]. 


\begin{tabular}{|l|c|c|c|c|}
\hline \multirow{2}{*}{\begin{tabular}{c}
\multirow{2}{*}{$\begin{array}{c}\text { Criteria } \\
\text { parameters }\end{array}$} \\
\cline { 2 - 5 }
\end{tabular}} & $\begin{array}{c}\text { Reliability of } \\
\text { system } \\
(\mathbf{1 - 1 0})\end{array}$ & $\begin{array}{c}\text { Flexibility of } \\
\text { system } \\
(\mathbf{1 - 1 0})\end{array}$ & $\begin{array}{c}\text { Equipment } \\
\text { cost } \\
\text { (EUR) }\end{array}$ & $\begin{array}{c}\text { Layout } \\
\text { utilization } \\
\text { (\% of current) }\end{array}$ \\
\hline Weight & 20 & 20 & 30 & 30 \\
\hline Objective & Maximize & Maximize & Minimize & Minimize \\
\hline Function type & Linear & Linear & Linear & Linear \\
\hline $\begin{array}{l}\text { Indifference } \\
\text { threshold }\end{array}$ & 0 & 0 & 500 & 5 \\
\hline $\begin{array}{l}\text { Preference } \\
\text { threshold }\end{array}$ & 9 & 9 & 20000 & 100 \\
\hline
\end{tabular}

Table 3. Criteria weights and parameters

When decision-maker defines his/her preferences (criteria weights) the HUMANT algorithm ranks the alternatives and returns three top-ranked alternatives to decision-maker, as presented on Fig. 5. In this case, the HUMANT algorithm selected three variants with highest priorities (Fig. 6): "Variant 4", "Variant 5", and "Variant 2". Although the "Variant 2 " is the cheapest improvement variant, its high layout utilization and low reliability made it the third ranked alternative.

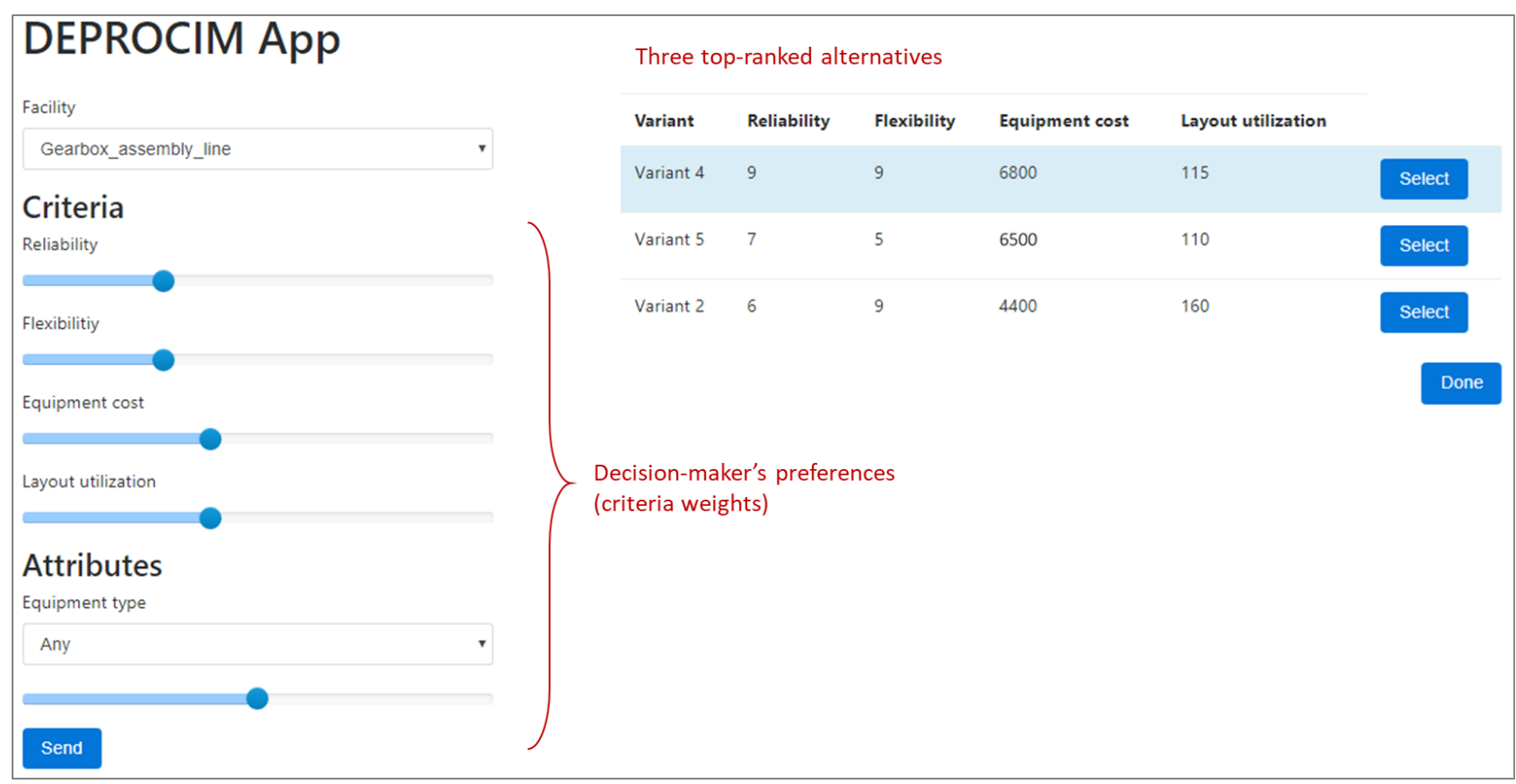

Fig. 5. Web application for the definition of the criteria weights with the results of the priority selection

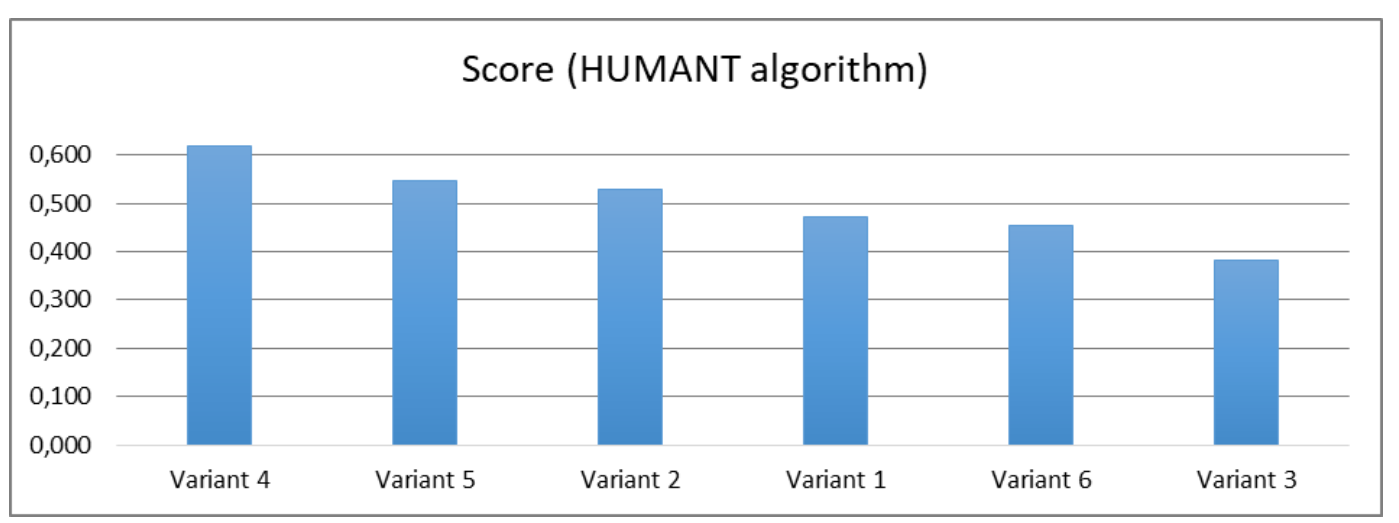

Fig. 6. Scores of the improvement variants by HUMANT algorithm (higher score = better) 
It is important to note, that top-ranked improvement variant doesn't represent the best solution, but rather the best compromise based on the preferences of the decision-maker. In this case, the best compromise is "Variant 4: Development and installation of display guidance for workers to enable flexible work amount on working stations and adaptive number of parts on working stations. It is monitored and driven by RFID system. Collaborative manipulator development and installation on working station with heavy parts". The second ranked is "Variant 5: Development and installation of material handling system for increased speed and accuracy of material and parts delivery on assembly stations, supermarkets. Development of electronic warehouse level triggers for self-organizing supply process".

Both of these variants will be realized in the Laboratory with the funds of the DEPROCIM project. Real-world implementation of these variants will help to validate developed DEPROCIM procedure, since the simulated outcomes can be compared with the real results. "Variant 2" will be realized in some further research, since the project funds are constraint in realization of all three variants.

\section{Conclusion}

In this paper, application of the integrative procedure for management of production and service improvement process has been presented on the Case Study of improvement of the gearbox assembly line. This procedure has been developed and experimentally tested as a part of the DEPROCIM project. The six improvement variants were proposed for the gearbox assembly line, and evaluation table for decision-making process has been made. The decision-maker's preferences determined criteria weights and submitted the problem to the HUMANT algorithm. The algorithm resulted with the scores for variants, thus obtaining their ranks. The three top-ranked variants are suggested to the decision-maker by using specially developed Web application. With this Case Study, it has been demonstrated how different improvement variants of production or assembly process can be mutually compared and ranking can be made based on the preferences of the decision-maker. By defining the decision-makers preferences, a subjectivism enters the analysis. However, this subjectivism is crucial, because if the company is willing to invest a lot into production improvement solutions, then criterion "cost" (with minimization aim) can get a low weight, but sometimes a low-cost improvement are needed, and in that case the criterion "cost" will get a high weight. Since this kind of subjectivism represents a real-world decisionmaking, the developed DEPROCIM procedure has a significant potential for real-world industrial applications. So, further research is aimed at implementing DEPROCIM procedure in the industrial case studies.

\section{Acknowledgments}

This work has been fully supported by the Unity Through Knowledge Fund (UKF), 1C My First Collaboration Grant, under the project 11/17 Development of integrative procedure for management of production and service improvement process.

\section{References}

[1] Mourtizs, D. (2016). Challenges and future perspectives for the life cycle of manufacturing networks in the mass customisation era, Logistics Research, 2016, 9.1: 2.

[2] Womack, J. P.; Jones, D.T.; Roos, D. (1990). The Machine that Changes the World: The Story of Lean production, HarperCollins Publishers, New York.

[3] Netland, T. H. (2013). Company specific production systems: Managing production improvement in global firms, University of Science and Technology Management Department of Industrial Economics and Technology Management, Trondheim, Norway.

[4] Veza I.; Mladineo M.; Gjeldum N. (2016). Selection of the basic Lean tools for development of Croatian model of innovative smart enterprise, Technical Gazzete, Vol. 23., No. 5.

[5] Womack, J.P.; Jones, D.T. (2003). Lean thinking, Free Press.

[6] Berger Roland strategy consultants. (2014). Industry 4.0. The new industrial revolution. How Europe will succeed, https://www.rolandberger.com/publications/publication_pdf/roland_berger_tab_industry_4_0_20140403.pdf, Accessed 05.03.2017.

[7] Kagermann, H. (2014). How Industrie 4.0 will coin the economy of the future: The results of the german High-tech strategy's and Strategic initiative Industrie 4.0, Royal Academy of engineering, London, http://www.raeng.org.uk/publications/other/henning-kagerman-acatech-presentation, Accessed 20.02.2017.

[8] International Atomic Energy Agency. (2006). Management of continual improvement for facilities and activities: A structured approach, http://www-pub.iaea.org/mtcd/publications/pdf/te_1491_web.pdf, Accessed 15.02.2017.

[9] Potocki K. A., Brocato R.C. (1995). A system of management for organizational improvement." Johns Hopkins APL technical digest, Vol. 16., No. 4.

[10] Micieta, B.; Stollmann, V. (2009). Design and improvement of production processes, DAAAM International Scientific Book 2009, DAAAM International, Vienna, Austria, 397-404.

[11] Trojanowska, J.; Pająk E. (2010). Using the theory of constraints to production processes improvement. 7th International DAAAM Baltic Conference on industrial engineering, 22-24.04.2010, Tallinn, Estonia. 
[12] Park, H.S.; Mun, S.H.; Choi, H.W.M Park, S.K. (2009). Development of a suitable manufacturing system for developing country. Annals of DAAAM \& Proceedings 2009, 541-542.

[13] Rother M.; Shook J. (2003). Learning to See, The Lean Enterprise Institute, Cambridge, MA USA

[14] Talbi, E.G. (2009). Metaheuristics - From Design to Implementation, John Wiley \& Sons, New York, USA

[15] Zitzler, E.; Laumanns, M.; Thiele, L. (2001). SPEA2: Improving the Strength Pareto Evolutionary Algorithm for Multiobjective Optimization. Proceedings of the EUROGEN'2001, Athens, Greece

[16] Phelps, S.; Koksalan M. (2003). An interactive evolutionary metaheuristic for multiobjective combinatorial optimization. Management Science, 49, 1726-1738.

[17] Deb, K.; Kumar, A. (2007). Interactive evolutionary multi-objective optimization and decision-making using reference direction method. Proceedings of the 9th annual conference on Genetic and evolutionary computation GECCO '07, 781-788

[18] Eppe, S. (2009). Integrating the Decision Maker's Preferences into Multi Objective Ant Colony Optimization. Proceedings of the 2nd Doctoral Symposium on Engineering Stochastic Local Search Algorithms - SLS 2009, Bruxelles, Belgium.

[19] Sörensen, K.; Springael, J. (2014). Progressive multi-objective optimization. International Journal of Information Technology and Decision Making, 13, 917-936

[20] Coello, C. A. C.; Lamont, G. B.; Van Veldhuizen, D.A. (2007). Evolutionary Algorithms for Solving MultiObjective Problems. New York: Springer.

[21] Brans, J. P.; Mareschal, B.; Vincke, P. H. (1984). PROMETHEE - a new family of outranking methods in multicriteria analysis. Operational Research IFORS 84, Amsterdam, Netherlands

[22] Mladineo, M.; Veža, I.; Gjeldum, N. (2015). Single-Objective and Multi-Objective Optimization using the HUMANT algorithm. Croatian Operational Research Review 6: 459-473

[23] Dorigo, M.; Maniezzo, V.; Colorni, A. (1996) The Ant System: Optimization by a colony of cooperating agents. IEEE Transactions on Systems, Man, and Cybernetics - Part B, 26, 1-13.

[24] Mladineo, M.; Veza, I.; Gjeldum, N. (2017). Solving partner selection problem in cyber physical production networks using the HUMANT algorithm. International Journal of Production Research.

[25] Gjeldum, N.; Mladineo, M.; Crnjac, M.; Aljinovic, A. (2018). Towards equipping an assembly line with Industry 4.0 concept elements in laboratory environment. LSS 2018, 24-25.05.2018, Opatija, Croatia.

[26] Veza, I.; Gjeldum, N.; Mladineo, M. (2018). Inovativno pametno poduzece [Innovative Smart Enterprise]. Split, Croatia: FESB. 